\title{
Decline of the lung function related to the type of tobacco smoked and inhalation
}

\author{
P Lange, S Groth, J Nyboe, J Mortensen, M Appleyard, G Jensen, P Schnohr
}

\begin{abstract}
Data from a five year follow up study on 4372 smokers and 3753 non-smokers were analysed to investigate the influence of the type of tobacco smoked and whether the subjects said they inhaled or not on the decline in forced expiratory volume in one second $\left(\mathrm{FEV}_{1}\right)$. The study sample comprised 1492 smokers of plain cigarettes and 1936 smokers of filter cigarettes, 1711 smokers of cheroots or cigars, and 233 male pipe smokers. Over the five years, smokers, especially those who said that they inhaled, had a higher rate of decline of $F V_{1}$ than non-smokers, in whom the average decline in $F E V_{1}$ was $25 \mathrm{ml} /$ year for women and $30 \mathrm{ml} /$ year for men. There was no significant difference in the decline in FEV 1 between filter cigarette smokers and plain cigarette smokers. The decline in $F E V_{1}$ in cigar or cheroot smokers was the highest for all the smoking groups, and associated with a very high tobacco consumption in this group. Among pipe smokers who inhaled, the decline in $\mathrm{FEV}_{1}$ was slightly higher than in the cigarette smokers, whereas non-inhaling pipe smokers had a decline in $F_{1} V_{1}$ that was similar to that of nonsmokers. In general, the smokers who said that they did not inhale had a smaller decline in $F E V_{1}$ than those who said that they did. The effect of inhalation varied in magnitude in different smoking groups, being most pronounced in pipe smokers.
\end{abstract}

Copenhagen City Heart Study, Medical Department $B$ and Department of Clinical Physiology and Nuclear Medicine, Rigshospitalet, and Medical Department P/Chest Clinic, Bispebjerg Hospital, Copenhagen, Denmark $P$ Lange $S$ Groth

J Nyboe

J Mortensen

M Appleyard

G Jensen

P Schnohr

Address for correspondence: Dr Peter Lange, Medical Department $B$,

Rigshospitalet, Blegdamsvej 9, DK-2100, Copenhagen $\varnothing$, Denmark.

Accepted 20 October 1989 comparing high tar or medium tar with lower tar cigarettes or filter with plain cigarettes. In most of these studies phlegm production has correlated positively with tar yield and the absence of filters. ${ }^{3-7}$ The relation of tar yield and lack of filter to ventilatory function, however, has been inconsistent. In a reanalysis ${ }^{8}$ of cross sectional data from the Whitehall study ${ }^{9}$ Lee showed that smokers of lower tar cigarettes had a slightly higher forced expiratory volume in the first second $\left(\mathrm{FEV}_{1}\right)$ than smokers of high tar cigarettes. But in three other studies, ${ }^{10-12}$ two of them longitudinal, there was no significant association between tar content or use of filters and FEV

The aim of our study was to analyse the association between decline in FEV during a five year follow up and smoking of cigars or cheroots, pipes, filter cigarettes, and non-filter cigarettes. As inhalation may affect the relation of smoking to the decline in $\mathrm{FEV}_{1}$, inhaling versus not inhaling was a further variable in the analysis.

\section{Methods}

POPULATION

A prospective epidemiological study, the Copenhagen City heart study, was initiated in 1976. The participants were selected from among 90000 people living in a defined area around Rigshospitalet, the University Hospital of Copenhagen. A sample of 19698 subjects aged 20 years or more was selected at random after age stratification. The sample fraction was highest $(50 \%)$ for persons aged 40-69 years. The subjects were invited by letter to an examination on a specific date during the period 1 March 1976 to 31 March 1978 and invited again five years later during the period 6 April 1981 to 7 September 1983. A total of $14223(74 \%$ of those invited) attended the first examination and $12698(70 \%$ of those invited) attended the second examination. Details of the selection procedure and a description of non-responders have been given elsewhere, together with the questionnaire and the complete examination programme. ${ }^{1314}$ From the total sample of 11135 subjects who attended both examinations the following subjects were excluded: (a) 344 persons with a history of bronchial asthma; (b) 1866 persons who at either examination said that they smoked more than one type of tobacco, or who changed the type of tobacco they smoked between the two examinations; (c) 626 subjects who stopped, started, or restarted smoking during the observation period; (d) four women who smoked a pipe; and (e) 170 subjects with incomplete data for the analysis. The final study sample comprised 4372 smokers and 3753 non-smokers. 


\section{PULMONARY FUNCTION}

$\mathrm{FEV}_{1}$ was recorded on the same electronic spirometer (Monaghan N 403, Littleton, Colorado) at the two examinations; this was calibrated daily. At least two measurements had to be within $5 \%$ of each other. The largest volume was used in the analysis.

\section{QUESTIONNAIRE ON SMOKING HABITS}

On both occasions participants were asked to report the form and type of the tobacco they smoked and if they inhaled while smoking. They were not asked if they had smoked different kinds of tobacco before the first examination. Subjects were then divided into the following groups: NS: Non-smokerssubjects who did not smoke tobacco at either examination; CIGP: subjects smoking only plain (non-filter) cigarettes during the observation period; CIGF: subjects smoking only filter cigarettes during the observation period; CER: subjects smoking only cigars, cheroots, or cigarillos during the observation period; PIPE: men smoking only a pipe during the observation period.

The following equivalents for the tobacco content were used: one plain or filter cigarette $=1 \mathrm{~g}$; one cigar $=5 \mathrm{~g}$; one cheroot or cigarillo $=3 \mathrm{~g} ; 1 \mathrm{~g}$ of pipe tobacco $=1 \mathrm{~g}$. The mean value for daily tobacco consumption reported at the two examinations was used in the analyses.

SOCIAL STATUS AND ALCOHOL CONSUMPTION As both socioeconomical status and alcohol consumption might be associated with lung function, ${ }^{15-17}$ these variables were included in the analysis. As an indicator of socioeconomical status we used the duration of school education as reported at the first examination.

\section{STATISTICAL METHODS}

For each subject the difference in $\mathrm{FEV}_{1}$ between the first and the second examination was divided by the precise length of the observation period to obtain an estimate of the annual decline in $\mathrm{FEV}_{1}\left(\triangle \mathrm{FEV}_{1}\right.$ in millilitres). We performed a separate multiple linear regression analysis of $\triangle F E V$, for men and women. The analysis covered both non-smokers and smokers and focused on the contribution of a given type of tobacco to $\triangle F E V_{1}$. The dependent variable was $\triangle F E V_{1}$ and the independent varia- bles of interest were the different smoking groups, generated by combining the use or non-use of inhalation ( + and - ) with the type of tobacco smoked (CIGP, CIGF, CER, PIPE) (thus there were eight smoking groups for men and six for women). Membership of these groups was indicated by eight binary variables for men $\left(x_{\mathrm{CIGP}+}, x_{\mathrm{CIGP}-} ; x_{\mathrm{CIGF}+}, x_{\mathrm{CIGF}-} ; x_{\mathrm{CER}+}\right.$, $\left.x_{\mathrm{CER}-} ; x_{\mathrm{PIPE}+}, x_{\mathrm{PIPE}-}\right)$ and six for women $\left(x_{\mathrm{CIGF}}{ }^{+}\right.$, $\left.x_{\mathrm{CIGF}-} ; x_{\mathrm{CER}+}, x_{\mathrm{CER}-}\right)$, assigned the value 1 for those belonging to a particular group and 0 otherwise.

Additional independent variables included in the regression model (the confounders) were: age ( $x_{\mathrm{a}}$ in years), height $\left(x_{\mathrm{h}}\right.$ in $\left.\mathrm{cm}\right)$, education ( $x_{e}$ in years), and daily alcohol consumption ( $x_{\text {alc }}$ in drinks/day). $\mathrm{FEV}_{1}$ was not included as a confounder in the regression model in the first examination, as suggested by Vollmer. ${ }^{18}$

The regression model for men was:

$\Delta \mathrm{FEV}_{1}=\mathrm{C}_{0}+\mathrm{C}_{1} \cdot x_{\mathrm{CIGP}}+\mathrm{C}_{2} \cdot x_{\mathrm{CIGP}-}+\mathrm{C}_{3} \cdot x_{\mathrm{CIGF}}+\ldots$ $+\mathrm{C}_{8} \cdot x_{\mathrm{PIPE}-}+\mathrm{C}_{9} \cdot x_{2}+\mathrm{C}_{10} \cdot x_{\mathrm{h}}+\mathrm{C}_{11} \cdot x_{\mathrm{e}}+\mathrm{C}_{12} \cdot x_{\mathrm{alc}}$.

The regression model for women was similar, except for the lack of variables describing pipe smoking. The question whether the above model could be simplified by reducing the number of smoking groups-for example, by disregarding the distinction between inhalers and non-inhalers-was evaluated by analysis of variance. A significance level of $5 \%$ was used.

The fit of the regression models was tested by plotting the residuals against the predicted values of $\triangle \mathrm{FEV}_{1}$ and against each of the independent variables included. We investigated whether the fit of the data could be improved by expanding the models with first order interaction terms, but found no significant improvement.

\section{Results}

At the first examination plain cigarette smokers had the lowest $\mathrm{FEV}_{1}$ as a percentage of their predicted value, inhaled more frequently, and consumed slightly more alcohol than did subjects in the other groups (table 1).

The mean daily consumption of tobacco and the unadjusted mean annual decline in $\mathrm{FEV}_{1}$ in the different smoking and inhalation groups is given in table 2 . In all smoking groups the inhalers consumed more tobacco than the noninhalers. The highest daily tobacco consumption was seen in the cigar and cheroot smokers. $\triangle \mathrm{FEV}_{1}$ was lowest in non-smokers and highest

Table 1 Characteristics of the subjects according to smoking group (inhalation given as a frequency, other variables as arithmetical means)

\begin{tabular}{|c|c|c|c|c|c|c|c|c|c|}
\hline \multirow[b]{2}{*}{$\begin{array}{l}\text { Smoking group: } \\
(n)\end{array}$} & \multicolumn{4}{|l|}{ Women } & \multicolumn{5}{|l|}{ Men } \\
\hline & $\begin{array}{l}N S \\
(2417)\end{array}$ & $\begin{array}{l}\text { CIGP } \\
(703)\end{array}$ & $\begin{array}{l}\text { CIGF } \\
(1462)\end{array}$ & $\begin{array}{l}C E R \\
\text { (404) }\end{array}$ & $\begin{array}{l}N S \\
(1336)\end{array}$ & $\begin{array}{l}\text { CIGP } \\
\text { (789) }\end{array}$ & $\begin{array}{l}\text { CIGF } \\
(474)\end{array}$ & $\begin{array}{l}\text { CER } \\
(307)\end{array}$ & $\begin{array}{l}P I P E \\
\text { (233) }\end{array}$ \\
\hline $\begin{array}{l}\text { Age (y) } \\
\text { Tobacco (g/day) } \\
\text { Alcohol (drinks/day) } \\
\text { Education (years) } \\
\text { Inhalation }(\%) \\
\text { FEV }_{1} \% \star\end{array}$ & $\begin{array}{c}53 \cdot 6 \\
0 \\
0 \cdot 3 \\
8 \cdot 5 \\
\\
97 \cdot 6\end{array}$ & $\begin{array}{c}50 \cdot 4 \\
13 \cdot 6 \\
0 \cdot 5 \\
8 \cdot 1 \\
84 \\
86 \cdot 1\end{array}$ & $\begin{array}{c}48 \cdot 1 \\
12 \cdot 9 \\
0 \cdot 4 \\
8 \cdot 5 \\
76 \\
91 \cdot 3\end{array}$ & $\begin{array}{r}59 \cdot 1 \\
31 \cdot 8 \\
0 \cdot 4 \\
8 \cdot 2 \\
22 \\
94 \cdot 5\end{array}$ & $\begin{array}{c}52 \cdot 3 \\
0 \\
1 \cdot 3 \\
8 \cdot 9 \\
98 \cdot 4\end{array}$ & $\begin{array}{l}51 \cdot 1 \\
17 \cdot 3 \\
2 \cdot 3 \\
8 \cdot 4 \\
93 \\
88 \cdot 7\end{array}$ & $\begin{array}{l}46 \cdot 8 \\
16 \cdot 9 \\
1.9 \\
8 \cdot 7 \\
90 \\
91 \cdot 9\end{array}$ & $\begin{array}{c}56 \cdot 9 \\
37 \cdot 2 \\
1 \cdot 7 \\
8 \cdot 6 \\
46 \\
92 \cdot 0\end{array}$ & $\begin{array}{c}53 \cdot 7 \\
15 \cdot 9 \\
1 \cdot 3 \\
8 \cdot 8 \\
54 \\
97 \cdot 0\end{array}$ \\
\hline
\end{tabular}

*As \% of predicted values, obtained by estimating the regression of $F E V_{1}$ on age and height among symptomless never smokers from the Copenhagen City heart study. The estimates were: for women $\mathrm{FEV}_{1}(\mathrm{ml})=410-27 \cdot 6 \times$ age $(\mathrm{y})+21 \cdot 2 \times \mathrm{height}(\mathrm{cm})$; for men $\mathrm{FEV}_{1}(\mathrm{ml})=-469-35 \cdot 2 \times$ age $(\mathrm{y})+32.0 \times$ height $(\mathrm{cm})$ NS-non-smokers; CIGP-plain cigarette smokers; CIGF-filter cigarette smokers; CER-cigar or cheroot smokers; PIPEpipe smokers. 
Table 2 Average daily tobacco consumption and decline in $F E V_{1}\left(\Delta F E V_{1}\right)$ according to the type of tobacco smoked and whether smoke was inhaled

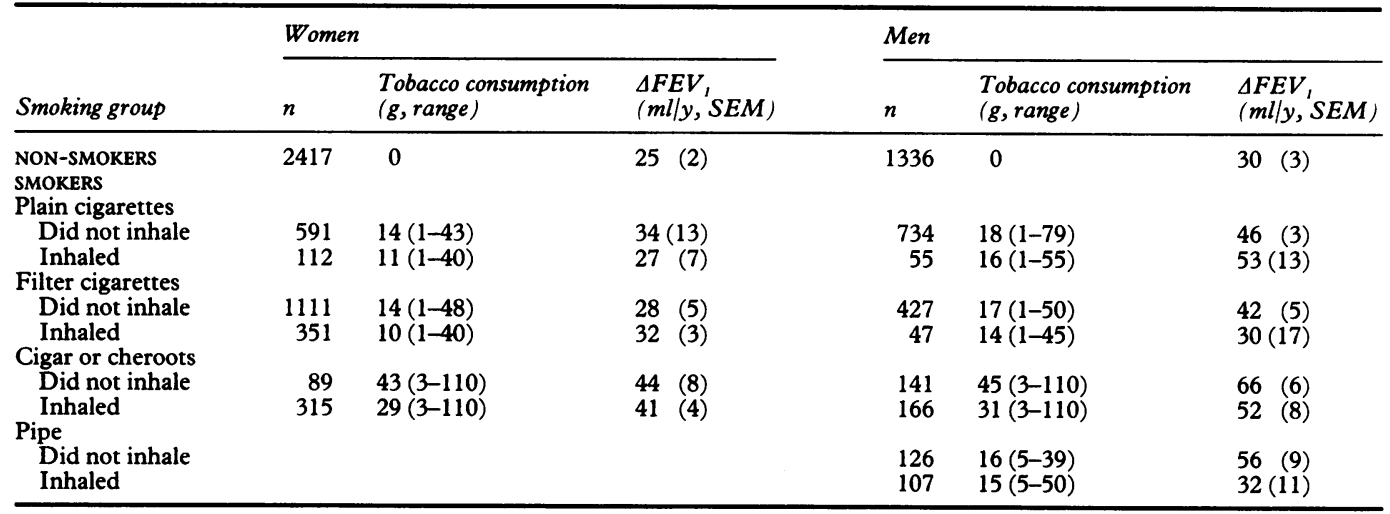

in cigar and cheroot smokers in both sexes. Generally, the smokers who inhaled had a higher decline in $\mathrm{FEV}_{1}$ than those who did not.

The results of the multiple linear regression analysis of decline in $\mathrm{FEV}_{1}$ are given in table 3. All groups of smokers who reported that they inhaled experienced a significantly higher decline in $\mathrm{FEV}_{1}$ than the non-smokers. The decline in $\mathrm{FEV}_{1}$ among the non-inhalers was not significantly higher than among the nonsmokers for any type of tobacco, though the decline in cigar and cheroot smokers almost reached the $5 \%$ significance level. When no distinction between the type of tobacco was made, female non-inhalers showed a significantly greater decline in $\mathrm{FEV}_{1}$ than the nonsmokers. Among male non-inhalers the decline in $\mathrm{FEV}_{1}$ was about $9 \mathrm{ml}$ a year greater than among non-smokers, but this difference was not significant.

The contribution of smoking to the decline in $\mathrm{FEV}_{1}$ appeared to be higher among cigar and cheroot and pipe smokers who inhaled than among cigarette smokers who inhaled. This possibility was explored further in both sexes separately by additional regression analyses. The first analysis compared cigarette smokers who inhaled with cigar and cheroot smokers who inhaled; the second analysis compared cigarette smokers who inhaled with pipe smokers who inhaled. None of the differences in decline in $F_{E V}$ reached significance, though

Table 3 Regression analysis of decline in FEV, $(\mathrm{ml} / \mathrm{y})$ on age, height, alcohol consumption, and the different types of tobacco smoking for smokers and non-smokers of both sexes (decline in non-smokers used as baseline)

\begin{tabular}{|c|c|c|c|c|}
\hline \multirow[b]{2}{*}{$\begin{array}{l}\text { Independent } \\
\text { variable }\end{array}$} & \multicolumn{2}{|l|}{ Women } & \multicolumn{2}{|l|}{ Men } \\
\hline & $\begin{array}{l}\text { Regression } \\
\text { coefficient (SEM) }\end{array}$ & $p$ & $\begin{array}{l}\text { Regression } \\
\text { coefficient (SEM) }\end{array}$ & $p$ \\
\hline Intercept & $-96 \cdot 7$ & & $-141 \cdot 0$ & \\
\hline Age $(y)$ & $1.2(0 \cdot 1)$ & $<0.001$ & $0.8 \quad(0.2)$ & $<0.001$ \\
\hline Height $(\mathrm{cm})$ & $0.4(0.2)$ & 0.05 & $0.7 \quad(0.3)$ & $<0.05$ \\
\hline Alcohol drinks/day & $0.4(1.7)$ & NS & $2 \cdot 1(0.9)$ & $<0.05$ \\
\hline Smoking groups: & & & & \\
\hline NON-SMOKERS & 0 & & 0 & \\
\hline $\begin{array}{l}\text { SMOKERS } \\
\text { Plain cigarettes }\end{array}$ & & & & \\
\hline $\begin{array}{l}\text { Did not inhale } \\
\text { Inhaled }\end{array}$ & $\begin{array}{r}13 \cdot 3(3 \cdot 8) \\
1.0(7 \cdot 8)\end{array}$ & $\begin{array}{l}<0.001 \\
\text { NS }\end{array}$ & $\begin{array}{l}14 \cdot 3(5 \cdot 6) \\
18 \cdot 3(15 \cdot 1)\end{array}$ & $\begin{array}{l}<0.005 \\
\text { NS }\end{array}$ \\
\hline Filter cigarettes & & & & \\
\hline $\begin{array}{l}\text { Did not inhale } \\
\text { Inhaled }\end{array}$ & $\begin{array}{r}11 \cdot 1(3 \cdot 1) \\
7 \cdot 1(4 \cdot 7)\end{array}$ & $\begin{array}{c}<0.001 \\
\text { NS }\end{array}$ & $\begin{array}{r}14.9(6.1) \\
-3.0(15.6)\end{array}$ & $\begin{array}{c}<0.05 \\
\text { NS }\end{array}$ \\
\hline $\begin{array}{l}\text { Cigars or cheroots } \\
\text { Did not inhale } \\
\text { Inhaled }\end{array}$ & $\begin{array}{r}20.6(9.0) \\
8.5(4.9)\end{array}$ & $\begin{array}{r}<0.05 \\
0.09\end{array}$ & $\begin{array}{ll}33.6 & (9 \cdot 6) \\
16.8 & (9.0)\end{array}$ & $\begin{array}{c}<0.001 \\
0.06\end{array}$ \\
\hline $\begin{array}{l}\text { Pipe } \\
\text { Did not inhale } \\
\text { Inhaled }\end{array}$ & & & $\begin{array}{r}27.9(10 \cdot 1) \\
-2 \cdot 1(10 \cdot 7)\end{array}$ & $\begin{array}{l}<0.01 \\
\text { NS }\end{array}$ \\
\hline
\end{tabular}

NS indicates $p>0 \cdot 1$. the difference between male cigar and cheroot smokers and cigarette smokers almost did $(\mathrm{p}=0.055)$.

The difference between the decline in $\mathrm{FEV}_{1}$ in plain cigarette smokers and filter cigarette smokers was not significant for either sex.

Except for male plain cigarette smokers, the decline in $\mathrm{FEV}_{1}$ was greater among smokers who inhaled than among those who did not inhale. The difference between inhalers and non-inhalers was only significant for pipe smokers.

The multiple regression analysis showed that $\Delta \mathrm{FEV}_{1}$ increased significantly with age, height, and (in men) with alcohol consumption. In both sexes the length of education was not significantly related to decline in $\mathrm{FEV}_{1}$.

\section{Discussion}

As in previous studies, we found that smokers have a steeper decline in $\mathrm{FEV}_{1}$ than nonsmokers, who on average had a decline of $25-30 \mathrm{ml}$ a year. ${ }^{1219}$ We have focused on the longitudinal changes in $\mathrm{FEV}_{1}$ rather than the cross sectional findings, because the latter are more difficult to interpret in aetiological terms. Even so, our results should be interpreted with caution as we cannot exclude the possibility that the choice of the type of tobacco was affected by the smoker's ventilatory function.

COMPARISON OF PLAIN AND FILTER CIGARETTES We found no significant difference in the decline in $\mathrm{FEV}_{1}$ between plain cigarette smokers and filter cigarette smokers.

At the time of our study the average tar content in Danish cigarettes was $35 \mathrm{mg}$ per cigarette for plain and $23 \mathrm{mg}$ per cigarette for filter cigarettes. The comparison in our analysis is therefore likely to reflect differences between high tar and medium tar cigarettes. Most previous studies have been unable to show any significant benefit from smoking lower tar cigarettes rather than high and medium tar cigarettes in terms of lung function $^{910}$ or mortality from chronic obstructive lung disease. ${ }^{20}$ In a survey of 365 subjects followed for more than 10 years, the maximum saving in the decline in $\mathrm{FEV}_{1}$ that was achieved by changing to lower tar cigarettes (a reduction of about $12 \mathrm{mg}$ tar per cigarette) was estimated 
to be less than $8 \mathrm{ml}$ a year. ${ }^{12}$ Our results also suggest that the tar content of cigarettes is relatively unimportant with respect to the development of ventilatory impairment. ${ }^{.10}$

CIGAR OR CHEROOT AND PIPE SMOKING

Cigar or cheroot and pipe smokers comprised $21.6 \%$ of our smokers. This is a much higher proportion than in most previous epidemiological surveys, ${ }^{23}$ but is typical for Denmark. ${ }^{21}$ In studies from other countries cigar and pipe smokers have been observed to have less impaired lung function ${ }^{1-3}$ and lower mortality from chronic obstructive lung disease than cigarette smokers. ${ }^{22}$

In the present study the decline in $\mathrm{FEV}_{1}$ in cigar and cheroot smokers was higher than in any other smoking group. This is in keeping with the fact that they consumed two to three times more tobacco than the cigarette smokers.

Pipe smokers who did not inhale had a decline in lung function similar to that seen in non-smokers. It has been suggested that it might be possible to train cigarette smokers to avoid inhalation when switching to pipe smoking. ${ }^{23}$ On the other hand, pipe smokers who said that they inhaled had slightly greater decline in FEV, than the cigarette smokers. Pipe smoking as such cannot therefore be regarded as harmless. These observations are in accordance with the finding of a very high mortality in Swedish pipe smokers, who inhale more frequently than pipe smokers in Britain. ${ }^{24}$

\section{INHALATION}

The importance of inhalation for the development of chronic obstructive lung disease has been the subject of some controversy. Doll and Peto reported a positive association between mortality from chronic obstructive lung disease and inhalation of tobacco smoke, ${ }^{22}$ whereas Beck et al, in a cross sectional study of cigarette smokers, were unable to relate inhalation to poorer lung function. ${ }^{11}$

In the present study subjects who inhaled, except for male smokers of plain cigarettes, had a steeper decline in $\mathrm{FEV}_{1}$ than those who did not inhale. The effect of inhalation varied between the smokers of different kinds of tobacco, and was significant only in pipe smokers. When considering all smoking groups separately, we found that the decline in FEV was not significantly greater in non-inhalers than among the non-smokers. But when we pooled data from all smoking groups the decline in lung function in female non-inhalers was significantly higher than in female nonsmokers. A similar, though non-significant, trend was observed in men. Our interpretation of these findings is that, although the decline of $\mathrm{FEV}_{1}$ is less accelerated in non-inhalers than in inhalers, the non-inhalers still have a higher risk of developing ventilatory impairment than non-smokers.

OTHER VARIABLES RELATED TO DECLINE IN FEV The decline of $F E V_{1}$ increased significantly with age and height, as reported in many previous longitudinal studies. ${ }^{25-27}$

Alcohol contributed significantly to the decline in $\mathrm{FEV}_{1}$ in men. In our previous study, in which only the data from subjects with relatively unchanged alcohol consumption throughout the observation period were analysed, a significant effect of alcohol on decline in $\mathrm{FEV}_{1}$ was observed in both sexes. ${ }^{17}$

Although we recently reported a weak but significant association between ventilatory function and socioeconomic status, ${ }^{28}$ we were unable in this analysis to show a significant association between the decline in lung function and formal education. A possible explanation for this may be the relatively short observation period in the present study, or it may be that in a sample of a general population factors associated with poor socioeconomic status influence ventilatory function mainly during childhood and adolescence.

\section{Conclusions}

In this study there was no significant difference in the decline in lung function between filter and plain cigarette smokers. Cigar and cheroot smokers had a slightly higher rate of decline of $\mathrm{FEV}_{1}$ than cigarette smokers, presumably because of a very high tobacco consumption. The effect of pipe smoking on decline in lung function was strongly inhalation dependent, being negligible in non-inhalers but slightly higher than in cigarette smokers in those who inhaled. Subjects who said they inhaled experienced a significantly higher rate of decline in $\mathrm{FEV}_{1}$ than non-smokers. The effect of inhalation differed in magnitude between smokers of different kinds of tobacco, being most pronounced in pipe smokers.

This study was supported by grants from the Danish Heart Foundation, the National Union for the Fight Against Lung Diseases, and the Danish Medical Research Council.

1 Royal College of Physicians. Smoking and health now. London: Pitman, 1971

2 Fletcher CM, Peto R, Tinker C, Speizer FE. The natural history of chronic bronchitis and emphysema. Oxford: Oxford University Press, 1976.

3 Comstock G, Brownlow WJ, Stone RW, Sartwell PE. Cigarette smoking and changes in respiratory findings. Arch Environ Health 1970;21:50-7.

4 Freedman S, Fletcher CM, Field GB. Effects of smoking modified cigarettes on respiratory symptoms and venmodified cigarettes on respiratory symptoms and ven-

5 Rimington J. Phlegm and filters. Br Med J 1972;ii:262-4.

6 Schenker MB, Samet JM, Speizer FE. Effect of cigarette ta content and smoking habits on respiratory symptoms in
conter women. Am Rev Respir Dis 1982;125:684-90.

7 Paoletti P, Camilli AE, Holberg CJ, Lebowitz MD. Respiratory effects in relation to estimated tar exposure from current and cumulative cigarette consumption. Chest 1985;88:849-55.

8 Lee PN. Low tar cigarette smoking. Lancet 1980;i:1365-6.

9 Higinbottam T, Clark TJH, Shipley MJ, Rose G. Lung function and symptoms of cigarette smokers related to tar yield and number of cigarettes smoked. Lancet 1980; i:409-12.

10 Sparrow D, Stefos T, Bosse R, Weiss ST. The relationship of tar content to decline in pulmonary function in cigarette 11 smokers. Am Rev Respir Dis 1983;127:56-8. Beck GJ, Doyle CA, Schachter EN. Smoking and lung
function. Am Rev Respir Dis 1981;123:149-55.

12 Peach H, Hayward DM, Ellard DR, Morris RW, Shak D Phlegm production and lung function among cigarette smokers changing tar groups during the 1970s. J Epidemiol Commun Health 1986;40:110-6.

13 Jensen G. Epidemiology of chest pain and angina pectoris [thesis]. Acta Med Scand 1984;suppl:682. 
14 Appleyard M, ed. The Copenhagen City Heart Study. Scand Soc Med 1989;suppl:41.

15 Higgins MW, Keller JB, Metzner HL. Smoking, socioeconomic status, and chronic respiratory disease. Am Rev Respir Dis 1977;116:403-10.

16 Lebowitz MD. Respiratory symptoms and disease related to alcohol consumption. Am Rev Respir Dis 1981;123:16-9.

7 Lange P, Groth S, Mortensen J, et al. Pulmonary function is influenced by heavy alcohol consumption. Am Rev Respir Dis 1988:137:1119-23.

18 Vollmer WM. Comparing change in longitudinal studies: adjusting for initial value. J Clin Epidemiol 1988;41:651-7.

19 Cotes JE. Lung function: principles and application in medicine. 4th ed. Oxford: Blackwell, 1979.

20 Lee PN, Garfinkel L. Mortality and type of cigarette smoked. J Epidemiol Commun Health 1981;35:16-22.

21 Gsell OR, Abelin T. Cigar and pipe smoking in relation to lung cancer and excess mortality. J Natl Cancer Inst lung cancer and
22 Doll R, Peto R. Mortality in relation to smoking: 20 years observations on male British doctors. $\mathrm{Br}$ Med J 1976; ii: $1525-36$.

23 Rodenstein DO, Stanescu DC. Pattern of inhalation of tobacco smoke in pipe, cigarette, and never smokers. $\mathrm{Am}$ tobacco smoke in pipe, cigarette,

24 Cartensen JM, Pershagen G, Eklund G. Mortality in relation to cigarette and pipe smoking: 16 years observation of 25,000 Swedish men. J Epidemiol Commun Health 1987;41:166-72

25 Oldham PD. Decline of FEV 1 . Thorax 1987;42:161-4.

26 Burrows B, Lebowitz MD, Camilli AE, Knudson RJ. Longitudinal changes in forced expiratory volume in one second in adults. Am Rev Respir Dis 1986;133:974-80.

27 Cole TJ. The influence of height on the decline in ventilatory function. Int J Epidemiol 1974;3:145-52.

28 Lange P, Groth S, Nyboe J, et al. Chronic obstructive lung disease in Copenhagen: cross-sectional epidemiological aspects. J Intern Med 1989;226:25-32. 